\title{
A Constitucionalização e a Internacionalização dos Direitos Fundamentais
}

\section{OSVALDO FERREIRA DE CARVALHO}

Advogado, Mestre em Direito pela PUC-Goiás, Professor de Direito Constitucional na PUC-Goiás.

DOI: $10.11117 / 22361766.43 .01 .04$

Submissão: 01.05.2011

Parecer 1: 26.08.2011

Parecer 2: 26.08.2011

Decisão Editorial: 26.08.2011

RESUMO: 0 artigo versará, precipuamente, sobre a evolução histórica e a constitucionalização dos direitos fundamentais, incluindo os direitos sociais. Far-se-á um escorço histórico dos direitos sociais nas Constituições brasileiras a partir da de 1934 com o escopo de fazer lembrar que as normas constitucionais consagradoras de direitos sociais são essenciais para a evolução e consolidação do Estado Constitucional, o qual é qualificado de social e democrático. Examinar-se-á, também, 0 processo de internacionalização dos direitos fundamentais, os quais são designados, na órbita internacional, como direitos humanos. Dedica-se a entender a progressiva constitucionalização do direito internacional, visto que os direitos fundamentais (abrangidos os sociais) devem ser tratados no âmbito de um direito constitucional integrado (ou globalizado) ao se detectar a elaboração dos contornos jurídicos de uma constituição global ao tomar como ponto de partida os direitos fundamentais que formariam uma constituição de direitos global com a consequente imposição de deveres.

PALAVRAS-CHAVE: Direitos fundamentais; direitos sociais; Constitucionalização; internacionalização.

ABSTRACT: The article will focus, primarily, on historical developments and the constitutionalization of fundamental rights, including social rights. Far will be a foreshortened history of social rights in the constitutions of Brazil from 1934 with the aim of reminding the standards enshrined in constitutional social rights are essential to the evolution and consolidation of the Constitutional State, which is classified as social and democratic. It will examine also the internationalization process of fundamental rights, which are designated on an international level, as human rights. Dedicated to understanding the progressive constitutionalization of international law, as fundamental rights (included the social rights) should be treated as part of a constitutional right integrated (or globalized) when detecting the preparation of legal contours of a global constitution to take as a starting point the fundamental rights that would form an overall constitution of rights and the consequent imposition of duties.

KEYWORDS: Fundamental rights; social rights; Constitutionalization; internationalization.

SUMÁRIO: Introdução; 1 Formação e evolução histórica dos direitos fundamentais; 2 A positivação dos direitos sociais fundamentais; 2.1 Os direitos sociais fundamentais nas Constituições brasileiras de 1934 a 1988; 3 Internacionalização dos direitos fundamentais; 3.1 A Declaração Universal dos Direitos Humanos de 1948; Conclusão; Referências. 


\section{INTRODUÇÃO}

A proposta deste artigo é fornecer elementos para explicar os motivos da internacionalização dos direitos fundamentais, os quais são designados, na órbita internacional, como direitos humanos ${ }^{1}$.

Procura-se clarificar e analisar os direitos fundamentais (ou direitos humanos) protegidos na esfera internacional ao cogitar-se mesmo da sua natureza de jus cogens ${ }^{2}$ em muitos casos.

Assim, as especificidades do direito internacional dos direitos humanos tornam-se claras quando conceitos, terminologias, fundamentos, critérios hermenêuticos e efeitos das normas de direitos humanos forem todos vistos sob a ótica do direito internacional dos direitos humanos.

Além disso, este artigo dedica-se, a um só tempo, a entender a progressiva constitucionalização do direito internacional, visto que os direitos fundamentais (abrangidos os sociais) devem ser tratados no âmbito de um direito constitucional integrado (ou globalizado) ao se detectar a elaboração dos contornos jurídicos de uma constituição global ao tomar como ponto de partida os direitos fundamentais que formariam uma constituição de direitos global com a consequente imposição de deveres. Tais direitos valeriam perante as instâncias políticas, mas também perante centros de poder econômico, conforme ensina Canotilho ${ }^{3}$.

\section{FORMAÇ̃̃O E EVOLUÇÃO HISTÓRICA DOS DIREITOS FUNDAMENTAIS}

Os direitos fundamentais (ou direitos humanos), embora existissem há bastante tempo - uma vez que são naturalmente inerentes ao ser humano e, desse modo, anteriores e superiores a toda ordem jurídica positivada -, somente com a recepção progressiva de textos ou documentos (denominados, genericamente, cartas ou declarações de direitos), passaram a ser formalmente reconhecidos, ganhando, portanto, dimensão jurídica.

1 DIMOULIS, Dimitri; MARTINS, Leonardo. Teoria geral dos direitos fundamentais. São Paulo: RT, 2007. p. 40; PIOVESAN, Flávia. Direitos humanos e o direito constitucional internacional. 7. ed. rev. ampl. e atual. São Paulo: Saraiva, 2006, p. 6. Há autores que sustentam que os direitos humanos são reconhecidos positivamente pelos sistemas jurídicos no plano nacional e internacional. SIQUEIRA JÚNIOR, Paulo Hamilton; OLIVEIRA, Miguel Augusto Machado de. Direitos humanos e cidadania. 2. ed. rev. e atual. São Paulo: RT, 2009. p. 22.

2 Segundo magistério de Hee Moon Jo sobre a expressão jus cogens, ele a define como "uma norma aceita e reconhecida pela comunidade internacional dos Estados no seu conjunto, com uma norma da qual nenhuma derrogação é permitida e que só pode ser modificada por uma norma de direito internacional geral da mesma natureza" (JO, Hee Moon. Introdução ao direito internacional. São Paulo: LTr, 2000. p. 19). A Convenção de Viena, ao aceitar a noção de jus cogens, deu uma demonstração de aceitação dos preceitos do direito natural. Com isso, se um tratado desrespeita uma norma considerada como jus cogens, ele é considerado nulo de pleno direito (arts. 52 e 53 da Convenção de Viena).

3 CANOTILHO, José Joaquim Gomes. "Brancosos" e interconstitucionalidade: itinerários dos discursos sobre a historicidade constitucional. Coimbra: Almedina, 2006. p. 289. 
Durante o período medieval, não faltaram documentos nos quais o monarca, cujo poder foi teoricamente ilimitado, reconheceu alguns limites para seu exercício em favor da igreja, dos senhores feudais ou das comunidades locais. Conforme ensina Antonio Enrique Pérez Luño, de todos os documentos medievais, sem dúvida, o que alcançou maior significação foi a Carta Magna, consistente em um pacto firmado em 1215 entre o Rei João Sem Terra e os bispos e barões ingleses ${ }^{4}$. Apesar de ter garantido tão somente privilégios feudais aos nobres ingleses, é considerada como marco de referência para algumas liberdades clássicas, como o devido processo legal, a liberdade de locomoção e a garantia da propriedade 5 .

Em seguimento, destacaram-se as declarações inglesas do século XVII, entre as quais a Petition of Rigths, de 1628, firmada por Carlos I; o Habeas Corpus Act, de 1679, assinado por Carlos II; e, finalmente, a mais importante de todas as declarações inglesas, o Bill of Rights, de 1689, promulgado pelo Parlamento ${ }^{6}$.

O termo "direitos fundamentais", droits fondamentaux, aparece na França no ano de 1770 no contexto do movimento político e cultural que conduziu à Declaração dos Direitos do Homem e do Cidadão de $1789^{7}$.

Assim, foi no século XVIII, com a vitória da revolução liberal na França e a independência das colônias inglesas nos Estados Unidos da América (EUA), que nasceram definitivamente os direitos fundamentais, a partir da Declaração do Bom Povo da Virgínia de 1776, seguida pela Declaração Francesa dos Direitos do Homem e do Cidadão de 1789. Após essas declarações, quase todas as Constituições no mundo passaram a dispor de uma declaração de direitos, a começar com a Constituição dos EUA de 17 de setembro de $1787^{\circ}$.

Segundo leciona Antonio Enrique Pérez Luño, as declarações dos EUA, bem como determinados documentos da Europa continental destinados a reconhecer a tolerância e a liberdade religiosa (como, por exemplo, a Paz de Augsburgo de 1555 e a Paz de Vestfália de 1648) e os pressupostos racionalistas e contratualistas da Escola de Direito Natural, exerceram uma influência direta sobre a Declaração dos Direito do Homem e do Cidadão, votada pela Assembleia Constituinte da França revolucionária no ano de $1789^{9}$. Nesse famoso texto, idêntico aos dos EUA, insiste-se no caráter universal dos direitos consagrados por seu fundamento racional, cuja validade se considera absoluta.

\footnotetext{
LUÑO, Antonio Enrique Pérez. Los derechos fundamentales. 8. ed. Madrid: Editorial Tecnos, 2004. p. 34. Idem, ibidem.

CUNHA JÚNIOR, Dirley da. Curso de direito constitucional. 2. ed. Salvador: JusPodivm, 2008. p. 541.

LUÑO, Antonio Enrique Pérez. Op. cit., p. 29. Conforme leciona Antonio Enrique Pérez Luño na página citada, a expressão alcançou singular importância na Alemanha, onde, sob a denominação dos Grundrechte, se articulou, de modo especial, após a Constituição de Weimar de 1919, ao sistema de relações entre o indivíduo e o Estado como fundamento de toda a ordem jurídico-política.

8 CUNHA JÚNIOR, Dirley da. Op. cit., p. 542.

9 LUÑO, Antonio Enrique Pérez. Op. cit., p. 36.
} 
Seus pressupostos são também individualistas: os direitos que correspondem ao homem por natureza são a liberdade, a propriedade, a segurança e a resistência à opressão. Somente a lei poderia limitar o desfrute dos direitos naturais de cada cidadão e, para assegurá-los a todos, foi concebida como expressão da vontade geral, nos moldes do ensinamento de Rousseau ${ }^{10}$.

A Declaração de 1789 fez parte, encabeçando-a, da primeira Constituição francesa de 1791, chamada por sua inspiração "girondina". Pouco tempo depois, a Constituição "jacobina" de 1793 iniciou com um catálogo de direitos do homem, muito importante por seu conteúdo democrático. No catálogo, são reconhecidos os direitos ao trabalho, à proteção contra a pobreza e à educação ${ }^{11}$.

Fábio Konder Comparato ensina que a Constituição francesa de 1848, retomando o espírito de certas normas das Constituições de 1791 e 1793, reconheceu algumas exigências econômicas e sociais da classe trabalhadora e que a instituição de deveres sociais do Estado para com os trabalhadores e com os necessitados em geral, estabelecida no art. 13, aponta para a criação do que viria a ser o Estado de Bem-Estar Social no século XX'12.

Ainda segundo o Professor Comparato, a Convenção de Genebra de 1864 inaugurou o que se convencionou chamar direito humanitário em matéria internacional, ou seja, "o conjunto das leis e costumes da guerra, visando a minorar o sofrimento dos soldados doentes e feridos, bem como de populações civis atingidas por um conflito bélico"13. Portanto, é a primeira introdução dos direitos humanos na esfera internacional ${ }^{14}$. Segundo Comparato, tem-se insistido ultimamente na tese de que o direito do estado de guerra já não poderia existir, por ser uma contradição nos termos: se a guerra constitui em si mesma um ilícito e, mais do que isso, um crime internacional, não faz sentido regular juridicamente as operações bélicas, pois "o Direito não pode organizar a prática de um crime"15. Todavia, Comparato argumenta que tal asserção não pode ser admitida. Para ele, se a guerra, no estado presente do direito internacional, constitui em si mesma um crime, nada impede que se reconheça a prática, por qualquer das partes beligerantes, de outros ilícitos durante o desenrolar do conflito ${ }^{16}$. Segundo as ilações do professor, a violação dos princípios e normas do direito humanitário, durante uma conflagração armada, pode representar, também, um crime de guerra ${ }^{17}$.

Idem, ibidem.

1 LUÑO, Antonio Enrique Pérez. Op. cit., p. 36-37.

12 COMPARATO, Fábio Konder. A afirmação histórica dos direitos humanos. 6. ed. rev. e atual. São Paulo: Saraiva, 2008. p. 54, 170.

13 Idem, p. 173

14 Idem, ibidem.

15 Idem, ibidem.

16 Idem, p. 174.

17 Idem, ibidem. Dalmo de Abreu Dallari, ao versar sobre a origem e atualidade do direito humanitário, ensina que, em razão dos seus princípios básicos e dos objetivos enunciados no início de seu advento e bastante ampliados no curso da história, bem como pelo seu conteúdo ético ligado aos valores fundamentais da 
Comparato ressalta que a plena afirmação de novos direitos humanos só veio a ocorrer no século XX, com a Constituição mexicana de 1917 e a Constituição de Weimar de $1919^{18}$.

A aprovação pela Assembleia-Geral das Nações Unidas da Declaração Universal de Direitos humanos em 10 de dezembro de 1948 constitui o principal feito no desenvolvimento da ideia contemporânea de direitos humanos (ou fundamentais), bem como a Convenção Internacional sobre a prevenção e punição do crime de genocídio aprovada um dia antes, também no quadro da ONU; logo, ambas formam os marcos inaugurais da nova fase histórica dos direitos humanos que se encontra em pleno desenvolvimento ${ }^{19}$.

Na Declaração Universal dos Direitos Humanos, a afirmação dos direitos fundamentais é, simultaneamente, universal ${ }^{20}$ e positiva: universal no sentido de que os destinatários dos direitos são todos os homens; e positiva no sentido de que os direitos deverão ser não apenas proclamados, mas efetivamente protegidos até mesmo contra o próprio Estado que os tenha violado.

Em 16 de dezembro de 1966, a Assembleia-Geral das Nações Unidas adotou 2 (dois) pactos internacionais de direitos humanos que desenvolveram pormenorizadamente o conteúdo da Declaração Universal de 1948: o Pacto Internacional sobre Direitos Civis e Políticos e o Pacto Internacional sobre Direitos Econômicos, Sociais e Culturais ${ }^{21}$. O sistema internacional de proteção

pessoa humana, o direito humanitário está estreitamente relacionado com os direitos humanos e às vezes pode coincidir com este (DALLARI, Dalmo de Abreu. Origem e atualidade do direito humanitário. Arquivos do Ministério da Justiça, Brasília, a. 51, n. 190, p. 18, jul./dez. 2006).

18 COMPARATO, Fábio Konder. Op. cit., p. 54.

19 Idem, p. 57. Contrario sensu, assinala-se a opinião de Flávia Piovesan ao revelar que o antecedente mais contributivo para a formação do Direito Internacional dos Direitos Humanos foi a Organização Internacional do Trabalho (OIT), criada após a Primeira Guerra Mundial, que tinha por finalidade promover padrões internacionais de condições de trabalho e bem-estar sociais (PIOVESAN, Flávia. Direitos humanos e o direito constitucional internacional, p. 111).

20 Em atenção à magistral lição de Boaventura de Sousa Santos, os direitos humanos não são universais na sua aplicação Atualmente, segundo o autor, são consensualmente identificados quatro regimes internacionais de aplicação de direitos humanos: o europeu, o interamericano, o africano e o asiático. Afirma, ainda, que apenas a cultura ocidental tende a formulá-los como universais e arremata que, "[...] enquanto forem concebidos como direitos humanos universais, os direitos humanos tenderão a operar como localismo globalizado e, portanto, como uma forma de globalização hegemônica. Para poderem operar como forma de cosmopolitismo, como globalização contra-hegemônica, os direitos humanos têm de ser reconceitualizados como multiculturais" (SANTOS, Boaventura de Sousa. Por uma concepção multicultural de direitos humanos. In: SANTOS, Boaventura de Sousa (Org.). Reconhecer para libertar: os caminhos do cosmopolitismo multicultural. Rio de Janeiro: Civilização Brasileira, 2003. p. 438-439 - grifo nosso).

Nessa linha de argumentação é, também, a posição de Samuel P. Huntington, ao asseverar que o crescente poder econômico dos países asiáticos os torna cada vez mais imunes às pressões ocidentais no que se refere aos direitos humanos e à democracia. Logo, para o autor, concebidos como direitos humanos universais, podem ser instrumentos do "choque de civilizações", ou seja, o que é universalismo para o ocidente é imperialismo para o resto (HUNTINGTON, Samuel P. O choque de civilizações e a recomposição da ordem mundial. Trad. M. H. C. Côrtes. Rio de Janeiro: Objetiva, 1996. p. 228, 243).

21 COMPARATO, Fábio Konder. Op. cit.,p. 279. Os dois pactos internacionais foram ratificados pelo Brasil pelo Decreto Legislativo $\mathrm{n}^{\circ}$ 226, de 12 de dezembro de 1991, sendo o Pacto Internacional sobre Direitos Econômicos, Sociais e Culturais promulgado pelo Decreto $n^{\circ} 591$, de 6 de julho de 1992, e o Pacto Internacional sobre Direitos Civis e Políticos promulgado pelo Decreto n 592, de 6 de julho de 1992. 
de direitos humanos apresenta, pois, instrumentos de âmbito global e regional. Adotando o valor da primazia da pessoa humana, esses sistemas se complementam com o fim de proporcionar a maior efetividade possível na tutela e promoção de direitos fundamentais ${ }^{22}$.

O instrumento regional de maior importância no sistema interamericano é a Convenção Americana de Direitos Humanos de 1969, também denominada Pacto de San José da Costa Rica ${ }^{23}$. Essa Convenção foi assinada em San José, Costa Rica, em 22 de novembro de $1969^{24}$. A convenção entrou em vigor em 1978 e somente os Estados-membros da Organização dos Estados Americanos (OEA) têm o direito de aderir à Convenção Americana ${ }^{25}$. Substancialmente, a Convenção America sobre Direitos Humanos reconhece e assegura um catálogo de direitos civis e políticos similar ao previsto pelo Pacto Internacional sobre Direitos Civis e Políticos ${ }^{26}$.

Segundo Flávia Piovesan, a Convenção Americana não enuncia, de forma específica, qualquer direito social, cultural ou econômico, limitando-se a determinar aos Estados que alcancem, progressivamente, a plena realização desses direitos, mediante a adoção de medidas legislativas e de outras medidas que se mostrem apropriadas, nos termos do art. 26 da Convenção ${ }^{27}$. Posteriormente, em 1988, a Assembleia-Geral da Organização dos Estados Americanos adotou um protocolo adicional à Convenção referente aos direitos sociais, econômicos e culturais - Protocolo de San Salvador -, que entrou em vigor em 16 de novembro de $1999^{28}$.

22 PIOVESAN, Flávia. Temas de direitos humanos. 3. ed. São Paulo: Saraiva, 2009. p. 33.

23 Idem, p. 44.

24 COMPARATO, Fábio Konder. Op. cit., p. 367. O Brasil aderiu à Convenção em 25 de setembro de 1992, que foi promulgada pelo Decreto $\mathrm{n}^{\circ} 678$, de 6 de novembro 1992.

25 PIOVESAN, Flávia. Temas de direitos humanos, p. 44. Segundo Flávia Piovesan, dos 35 Estados-membros da OEA 24 Estados são hoje partes da Convenção Americana sobre Direitos Humanos (PIOVESAN, Flávia. Temas de direitos humanos, p. 45.

26 COMPARATO, Fábio Konder. Op. cit., p. 367.

27 PIOVESAN, Flávia. Temas de direitos humanos, p. 46. 0 art. 26 da Convenção preceitua: "Os Estados-partes comprometem-se a adotar providências, tanto no âmbito interno como mediante cooperação internacional, especialmente econômica e técnica a fim de conseguir progressivamente a plena efetividade dos direitos que decorrem das normas econômicas, sociais e sobre educação, ciência e cultura, constantes da Carta da Organização dos Estados Americanos, reformada pelo Protocolo de Buenos Aires, na medidas dos recursos disponíveis, por via legislativa ou por outros meios apropriados". O artigo foi reproduzido da seguinte obra: CANÇADO TRINDADE, Antônio Augusto. A proteção internacional dos direitos humanos: fundamentos jurídicos e instrumentos básicos. São Paulo: Saraiva, 1991. p. 366.

28 O Estado brasileiro aderiu ao Protocolo, nos termos do art. 21 do Protocolo Adicional à Convenção Americana sobre Direitos Humanos em matéria de direitos econômicos, sociais e culturais (Protocolo de San Salvador), em 21 de agosto de 1996. Esse documento reforça, no âmbito do sistema interamericano de direitos humanos, o reconhecimento dos direitos humanos de segunda "geração" ou dimensão, a saber: direito ao trabalho (art. $6^{\circ}$ ), direitos sindicais (art. $8^{\circ}$ ), direito à Previdência Social (art. $9^{\circ}$ ), direito à saúde (art. 10), direito à alimentação (art. 12), direito à educação (art. 13), direito aos benefícios da cultura (art. 14), direitos à constituição e proteção da família (art. 15), direito da criança (art. 16), direito do idoso (art. 17), proteção dos deficientes (art. 18). 0 "Protocolo de San Salvador" pode ser consultado no seguinte site da Internet: <http://www.fd.uc.pt/igc/enciclopedia/documentos/instrumentos_regionais/america/protocolo_convencao_ direitos_economicos.pdf >. Acesso em: 10 set. 2009. 
Portanto, as declarações, convenções e pactos internacionais tiveram importância decisiva para a evolução e afirmação dos direitos fundamentais.

\section{A POSITIVAÇÃO DOS DIREITOS SOCIAIS FUNDAMENTAIS}

Ao longo do século XIX, o proletariado adquiriu protagonismo histórico à medida que avançou o processo de industrialização e, ao desenvolver uma consciência de classe, reivindicou alguns direitos econômicos e sociais perante os clássicos direitos individuais em que estes foram decorrentes do triunfo da revolução liberal burguesa. Logo, o direito ao trabalho, seu rendimento e a segurança social constituem novas exigências, cuja proteção jurídica se reclama. Sob este aspecto, pode-se considerar como a carta destes novos direitos o Manifesto Comunista, redigido por Marx e Engels no ano de $1848^{29}$.

Nesse mesmo ano (1848), a Constituição francesa da Segunda República, ao fazer eco dessas exigências e conectando com o teor da Constituição "jacobina" de 1793, quis representar a projeção dos princípios revolucionários de 1789 nas esferas social e econômica: se esta foi a declaração da liberdade, a de 1848 pretendia ser a da igualdade.

A marca do Manifesto Comunista repercute de forma evidente na Declaração dos Direitos do Povo Trabalhador e Explorado, que foi redigida no âmbito da Revolução Russa de 1917 e promulgada no dia 3 de janeiro de 1918 na antiga União das Repúblicas Socialistas Soviéticas (URSS). O texto da declaração, elaborado por Lênin, foi incorporado à Constituição soviética ao possuir as seguintes inovações ${ }^{30}$ :

(1) Declara abolidas a propriedade privada e a possibilidade de exploração do trabalho assalariado (capítulo II), em completa ruptura com as anteriores Constituições e declarações de direitos que garantiam a propriedade privada como elemento central;

29 LUÑo, Antonio Enrique Pérez. Op. cit.,p. 38. O manifesto sugere um curso de ação para uma revolução socialista por meio da tomada do poder pelos proletários. A história da humanidade seria constituída, em todos os tempos, por uma permanente luta de classes, como deixa bem claro a primeira frase do primeiro capítulo do Manifesto Comunista: "A história de toda sociedade existente até hoje tem sido a história das lutas de classes". Marx e Engels partem de uma análise histórica, distinguindo as várias formas de opressão social durante os séculos e situam a burguesia moderna como nova classe opressora. Não deixam, porém, de citar seu grande papel revolucionário, tendo destruído o poder monárquico e religioso valorizando a liberdade econômica extremamente competitiva e um aspecto monetário frio em detrimento das relações pessoais e sociais ao tratar o operário como uma simples peça de trabalho. Este aspecto, juntamente com os recursos de aceleração de produção (tecnologia e divisão do trabalho), destrói todo atrativo para o trabalhador, deixando-o completamente desmotivado e contribuindo para a sua miserabilidade e coisificação.Vocábulo consultado da Wikipédia, enciclopédia livre on-line. Disponível em: <http://pt.wikipedia.org/wiki/Manifesto_Comunista > Acesso em: 28 set. 2009. Para um maior aprofundamento acerca de alguns delineamentos do Manifesto Comunista, poderão ser mais bem elucidados no verbete "marxismo" na seguinte obra: BOBBIO, Norberto. Marxismo. In: BOBBIO, Norberto; MATTEUCCI, Nicola; PASQUINO, Gianfranco. Dicionário de política. Trad. Carmen C. Varriale et al. 11. ed. Brasília: UnB, v. 1, 1998. p. 738-744.

30 Tradução do texto para o português disponível em: <http://www.marxists.org/portugues/lenin/1918/01/17. html>. Acesso em: 28 set. 2009. 
(2) Estabelece um dever fundamental: o trabalho obrigatório para todos (capítulo II, 4);

(3) Estabelece um tratamento diferenciado dos titulares de direitos de acordo com a classe social, restringindo os direitos dos integrantes da classe burguesa (capítulo IV).

Essas inovações foram, portanto, confirmadas e completadas pela primeira Constituição soviética de 10 de julho de 1918, ao introduzir uma série de direitos sociais (art. $2^{\circ}$, capítulo $\vee$, itens 14 a 17) ${ }^{31}$.

A Declaração dos Direitos do Povo Trabalhador e Explorado introduziu as novidades anteriormente especificadas que destoaram, em sua substância - ao ignorar o reconhecimento de qualquer direito individual -, do desenvolvimento do constitucionalismo ocidental até então e, precipuamente, do subsequente, marcado pelo que se passou a chamar de economia de mercado e sua ênfase na autonomia e propriedade privadas ${ }^{32}$.

Deve-se atribuir à Constituição mexicana a primeira Constituição que garantiu uma longa lista de direitos sociais, sendo promulgada em 5 de fevereiro de 1917. Em seu primeiro capítulo, são encontrados direitos sociais que pouco se diferenciam de uma Constituição moderna, como a Constituição brasileira de $1988^{33}$.

Todavia, devem-se à Constituição da República de Weimar, de 11 de agosto de 1919, a sistematização e o reconhecimento, em termos definitivos, destes direitos. Demonstra-se isso pelo fato de haver a Constituição alemã - que se constituía em duas partes - dedicado toda a segunda parte (Parte II), dividida em cinco títulos (arts. 109-165), aos novos direitos econômicos e sociais, sob a denominação genérica de "Direitos e Deveres Fundamentais dos Alemães". Não foi por acaso que a chamada Constituição de Weimar tornou-se paradigmática do constitucionalismo do primeiro pós-guerra e ainda é o marco que separa duas épocas históricas: a do constitucionalismo liberal dos séculos XVIII e XIX e a do constitucionalismo social do século XX, que com ela adquiriu expansão universal ${ }^{34}$.

A Constituição de Weimar, efetivamente, representou inquestionável modelo de avanço constitucional na evolução histórica dos direitos sociais fundamentais de segunda dimensão, fonte do Estado do bem-estar social na Alemanha e, posteriormente, no Brasil, na Constituição de 1934.

31 A Constituição da República Soviética Federativa Socialista Russa de 1918 pode ser consultada em: <http:// www.marxists.org/history/ussr/government/constitution/1918/index.htm>. Acesso em: 28 set. 2009.

32 DIMOULIS, Dimitri; MARTINS, Leonardo. Op. cit., p. 32-33.

33 Idem, p. 32. Registram-se os seguintes exemplos hauridos do primeiro capítulo da Constituição mexicana de 1917: ensino primário gratuito nos estabelecimentos oficiais (direito à educação), direito ao trabalho com justa retribuição, etc. (México. Constitución Política de los Estados Unidos Mexicanos de 1917. Disponível em: <http://www.diputados.gob.mx/LeyesBiblio/pdf/1.pdf>. Acesso em: 16 set. 2009).

34 LUÑO, Antonio Enrique Pérez. Op. cit., p. 39-40. 


\subsection{Os diReitos Socials fundamentals nas Constituições brasileIRAS de 1934 a 1988}

A ordem jurídica brasileira do século XIX, embora tenha recebido os influxos dos movimentos internacionais, palmilhou caminho próprio com as peculiaridades referentes aos direitos sociais. A Constituição de 1824, outorgada pelo imperador, ainda que não tivesse propriamente o recorte de uma Constituição que reconhecesse e declarasse direitos sociais, limitou-se a garantir os "socorros públicos", a instrução primária universal e gratuita e a existência de colégios e universidades, ao se extrair da leitura dos incisos XXI, XXII e XXIII de seu art. $179^{35}$.

A primeira Constituição republicana de 1891, ao refletir o pensamento liberal da época, passou longe de toda a pretensão social, negando qualquer repercussão à Carta francesa de 1848, bem como reclamos sociais que se acumulavam, forjando os pressupostos sociais, jurídicos e econômicos para a formação de Estados socialistas e social-democráticos que pouco depois se apresentaram ao mundo ${ }^{36}$. Teve, pois, a Constituição de 1934 o claro propósito de fincar as pedras fundamentais do assim chamado Estado Social.

A Constituição brasileira de 1934, sob significativa influência da Constituição de Weimar, transcreveu desta Constituição vários artigos referentes aos direitos sociais e econômicos que, pela primeira vez na história do constitucionalismo brasileiro, cuidou no Título IV de normas alusivas à Ordem Econômica e Social.

A Constituição brasileira de 1937, outorgada por Getúlio Vargas, introduziu capítulo designado de "Ordem Econômica", sem o qualificativo "Social". Seu art. 136 dispunha que "o trabalho é um dever social", "que a todos seria garantido o direito de subsistir mediante o seu trabalho honesto" e que o Estado possuía o dever de protegê-lo, "assegurando-lhe condições favoráveis e meios de defesa". A precedência dada ao dever perante o direito indicia a natureza totalitária do regime ${ }^{37}$.

De acordo com a lição de José Ledur, com a Constituição de 1946, o Brasil reencontra-se com a democracia. Volta-se a prever título designado "Da Ordem Econômica e Social". O parágrafo único do art. 145 assegurava "trabalho que possibilite existência digna", e os dezessete incisos do art. 157 continham preceitos trabalhistas e previdenciários que, conforme o caput, seriam obedecidos pela legislação do trabalho e previdência social. O art. 158 reconhecia o direito de greve e o art. 159 dispunha sobre a liberdade de associação profissional ou sindical ${ }^{38}$.

35 NUNES JÚNIOR, Vidal Serrano. A cidadania social na Constituição de 1988: estratégias de positivação e exigibilidade judicial dos direitos sociais. São Paulo: Editora Verbatim, 2009. p. 57.

36 Idem, p. 58.

37 LEDUR, José Filipe. Direitos fundamentais sociais: efetivação no âmbito da democracia participativa. Porto Alegre: Livraria do Advogado, 2009. p. 76.

38 Idem, p. 76-77. 
A Constituição de 1967 foi inovadora quanto aos direitos sociais à medida que não mais se referia a preceitos a serem observados pela legislação ordinária. Assim fixava o art. 158: "A Constituição assegura aos trabalhadores os seguintes direitos, além de outros que, nos termos da lei, visem à melhoria de sua condição social: [...]". Seguiam-se vinte e um incisos com os distintos direitos trabalhistas, médico-assistenciais e previdenciários oriundos de relação de emprego. Normas que, antes da Constituição de 1967, se limitavam a preceitos endereçados ao legislador ordinário passaram a abrigar direitos de natureza constitucional ${ }^{39}$. A Emenda Constitucional $n^{\circ}$ 1, de 1969, não introduziu mudança significativa no rol dos direitos sociais, permanecendo praticamente inalterados os de natureza trabalhista e coletiva e similares à Constituição de 1967 as regras relativas à educação.

Agora, sem dúvida, a Constituição brasileira de 1988 deu um salto qualitativo de extraordinário significado no terreno dos direitos sociais ao incluí-los no rol dos direitos fundamentais e porque reconheceu novos direitos, resultantes da influência do movimento social na convocação da Assembleia Nacional Constituinte e no desenvolvimento de seus trabalhos. O aspecto quantitativo comparece na ampliação numérica dos direitos sociais. A leitura do art. $6^{\circ}$ mostra que o lazer e a segurança são direitos novos não reconhecidos em constituições anteriores. Mesmo o direito à saúde não era expressamente previsto anteriormente, muito embora algumas normas contivessem preceitos referentes a ele. A moradia passou a ser direito social fundamental por meio da EC 26, de 14.02.2000, positivando-se internamente direito já reconhecido em constituições estrangeiras e normas de direito internacional ${ }^{40}$.

39 Idem, p. 77.

40 Idem, p. 79. Historicamente, a Constituição mexicana de 5 de fevereiro de 1917 já previa o direito à moradia em seu art. $4^{\circ}, \S 5^{\circ}$, nestes termos: "Toda familia tiene derecho a disfrutar de vivienda digna y decorosa. La Ley establecerá los instrumentos y apoyos necesarios a fin de alcanzar tal objetivo" (México. Constitución Política de los Estados Unidos Mexicanos de 1917. Disponível em: <http://www.diputados.gob.mx/LeyesBiblio/pdf/1. pdf >. Acesso em: 16 set. 2009).

Ainda, no plano internacional, cumpre informar que a Constituição espanhola de 27 de dezembro de 1978 estabelece, também, em seu art. 47, o direito à moradia digna e adequada, vejamos o seu texto: "Artículo 47. Todos los españoles tienen derecho a disfrutar de una vivienda digna y adecuada. Los poderes públicos promoverán las condiciones necesarias y establecerán las normas pertinentes para hacer efectivo este derecho, regulando la utilización del suelo de acuerdo con el interés general para impedir la especulación" (Espanha. Constitución Española de 1978. Disponível em: <http://www.boe.es/aeboe/consultas/enlaces/ documentos/ConstitucionCASTELLANO.pdf>. Acesso em: 16 set. 2009).

Menciona-se, também, que a Constituição portuguesa de 2 de abril de 1976, tal qual a do México de 1917 e a da Espanha de 1978, expressamente faz alusão ao direito à moradia em seu art. $65^{\circ}, 1$. Embora utilize o vocábulo "habitação", que, para nós, não altera o alcance e sentido postulado pelo constituinte na feitura desse dispositivo ao preceituar, in verbis: "Todos têm direito, para si e para a sua família, a uma habitação de dimensão adequada, em condições de higiene e conforto e que preserve a intimidade pessoal e a privacidade familiar" (Portugal. Constituiçãa da República Portuguesa de 1976. Disponível em: <http:// www.tribunalconstitucional.pt/tc/crp.html>. Acesso em: 16 set. 2009).

Ingo Wolfgang Sarlet ensina que a Declaração Universal dos Direitos Humanos da ONU de 1948 constitui o marco, na esfera internacional, dos denominados direitos econômicos, sociais e culturais - entre os quais o direito à moradia - serem objeto de previsão expressa na condição de direitos humanos e fundamentais. Com efeito, de acordo com o art. XXV (1) da Declaração: "Todo ser humano tem direito a um padrão de vida capaz de assegurar-lhe, e à sua família, saúde e bem-estar, inclusive alimentação, vestuário, habitação, cuidados 
Quanto ao direito ao trabalho, verifica-se que obteve desdobramentos em seu conteúdo no próprio capítulo dedicado aos direitos sociais fundamentais, ou seja, do art. $7^{\circ}$ ao art. 11 da Constituição, destacando-se notável incremento do rol dos direitos fundamentais do trabalho.

José Ledur ressalta que a história dos direitos sociais no Brasil, da mesma forma ocorrida em países europeus, possui relação estreita com o direito ao trabalho e com as normas jurídicas que o disciplinam, especialmente as de direito do trabalho ${ }^{41}$. Segundo o autor, isso faz com que os direitos sociais, por vezes, sejam simplesmente confundidos com o direito do trabalho. A inserção de regras e princípios de direito do trabalho entre os direitos e garantias fundamentais (arts. $7^{\circ}$ a 11 da Constituição de 1988) prova a força do vínculo histórico entre os direitos sociais e o direito ao trabalho e seus desdobramentos em normas de direito do trabalho, previdenciário e coletivo ${ }^{42}$. No entanto, bem mais amplos são o objeto dos direitos sociais, conforme demonstra o art. 6o da CF/1988, e os desenvolvimentos que a maioria dos direitos ali reconhecidos obteve nos títulos concernentes à ordem econômica e, especialmente, à ordem social.

\section{INTERNACIONALIZAÇÃO DOS DIREITOS FUNDAMENTAIS}

Pérez Luño refere-se ao fenômeno da internacionalização dos direitos humanos (ou direitos materialmente fundamentais, sendo uma das espécies os direitos sociais, econômicos, culturais, etc.) como um dos pontos que mais poderosamente tem contribuído para caracterizar a atual etapa de positivação dos direitos humanos ${ }^{43}$. Para o jurista espanhol, trata-se de um processo ligado ao

médicos e os serviços sociais indispensáveis, e direito à segurança em caso de desemprego, doença, invalidez, viuvez, velhice ou outros casos de perda dos meios de subsistência em circunstâncias fora de seu controle". Para o jurista, a partir do citado dispositivo, no âmbito do direito internacional, o direito à moradia passou a ser objeto de reconhecimento expresso em diversos tratados e documentos internacionais, destacando-se, seja pela sua precedência cronológica, seja pela sua relevância, o Pacto Internacional dos Direitos Sociais, Econômicos e Culturais de 1966, também ratificado e incorporado ao direito interno brasileiro, em que, no art. 11, consta que "os Estados signatários do presente pacto reconhecem o direito de toda pessoa a um nível de vida adequado para si próprio e para sua família, inclusive alimentação, vestimenta e moradia adequadas, assim como a uma contínua melhoria de suas condições de vida" (SARLET, Ingo Wolfgang. O direito fundamental à moradia na Constituição: algumas anotações a respeito de seu contexto, conteúdo e possível eficácia. Revista de Direito do Consumidor, São Paulo, v. 46, p. 198, abr./jun. 2003).

Ademais, Ingo Sarlet leciona que duas conferências das Nações Unidas sobre assentamentos humanos marcaram a história da organização na luta por melhores condições de vida da população: a Habitat I, realizada em Vancouver, Canadá, entre os dias 31 de maio a 11 de junho de 1976, que originou a Declaração de Vancouver sobre Assentamentos Humanos; e a realizada em Istambul, Turquia, entre os dias 3 a 14 de junho de 1996, originando a Declaração de Istambul sobre Assentamentos Humanos, da qual resultou a assim designada Agenda Habitat II, considerado o mais completo documento na matéria. Por ocasião da Agenda Habitat II (Declaração de Istambul de 1996), além de reafirmado o reconhecimento do direito à moradia como direito fundamental de realização progressiva, faz remissão expressa aos pactos internacionais anteriores (art. 13) - Declaração Universal dos Direitos Humanos e o Pacto Internacional dos Direitos Econômicos, Sociais e Culturais -, houve minuciosa previsão quanto ao conteúdo e extensão do direito à moradia (art. 43), bem como sobre as responsabilidades gerais e específicas dos Estados signatários para a sua realização SARLET, Ingo Wolfgang. Op. cit., p. 199).

41 LEDUR, José Filipe. Op. cit., p. 80.

42 Idem, ibidem

43 Idem, p. 41. 
reconhecimento da subjetividade jurídica do indivíduo pelo direito internacional e, efetivamente, somente quando se admite a possibilidade de que a comunidade internacional possa entender questões que afetem não tanto aos Estados como tais, senão as de seus membros ao gerar um reconhecimento em escala internacional dos direitos humanos ${ }^{44}$. É necessário, portanto, partir da premissa de que qualquer atentado contra os direitos e liberdades da pessoa não é uma questão doméstica dos Estados, mas um problema de relevância internacional ${ }^{45}$.

Segundo lição de Dimitri Dimoulis e de Leonardo Martins, as principais dimensões da internacionalização podem ser resumidas da seguinte forma: (a) vasta produção normativa internacional em defesa dos direitos humanos (declarações, convenções, pactos, tratados, etc.); (b) crescente interesse das organizações internacionais pelos direitos humanos e criação de organizações cuja principal finalidade é promovê-los e tutelá-los; (c) criação de mecanismos internacionais de fiscalização de possíveis violações e de responsabilização de Estados ou indivíduos que cometem tais violações; (d) intensa produção doutrinária em âmbito internacional, incluindo debates de cunho político e filosófico, assim como análises estritamente jurídicas de dogmática geral e especial ${ }^{46}$.

Essa evolução contrapõe-se à validade do princípio do relacionamento binário entre o Estado e o indivíduo que governa a concepção tradicional dos direitos fundamentais. A introdução dos sujeitos do direito internacional e principalmente das organizações internacionais nessa relação torna mais complexas as questões do exercício e da garantia dos direitos fundamentais, vinculando-os a uma nova discussão e negociação do princípio da soberania nacional ${ }^{47}$. Segundo os autores supramencionados, as mudanças são múltiplas ao destacarem as seguintes ${ }^{48}$ :

a) Ampliação dos titulares de direitos ao permitir uma titularidade universal, independentemente da nacionalidade e do lugar de residência, princípio esse que conhece uma série de exceções e não exclui o reconhecimento de direitos "particularistas", em benefício de determinadas categorias de pessoas (mulheres, crianças, minorias étnicas, grupos indígenas, etc.);

b) Possibilidade de responsabilizar o Estado de forma externa, independentemente do acionamento de mecanismos de direito interno e da boa (ou má) vontade das autoridades estatais pelos instrumentos de fiscalização e responsabilização que ficam sob o encargo de comissões, Tribunais e outras autoridades internacionais;

44 LUÑO, Antonio Enrique Pérez. Op. cit., p. 41.

45 Idem, ibidem.

46 DIMOULIS, Dimitri; MARTINS, Leonardo. Op. cit., p. 40.

47 Idem, ibidem.

48 Idem, p. 40-41. 
c) Forte politização da matéria devido à necessidade de se realizarem contínuos compromissos entre os Estados e os atores internacionais, no intuito de oferecer efetividade aos direitos humanos no âmbito internacional, apesar da ausência de poder estatal e de instituições que executem diretamente normas internacionais.

No século $X X$, assim como no atual, produziu-se uma série de acontecimentos trágicos, gravemente lesivos à causa das liberdades, que tem potencializado o esforço dos homens e das nações a fim de estabelecer mecanismos internacionais de proteção dos direitos humanos. As catástrofes bélicas, a necessidade de reconhecer o direito de autodeterminação e o processo de descolonização dos povos, o esforço pela afirmação dos direitos da mulher, os graves atentados contra os direitos individuais praticados pelos sistemas totalitários (genocídio, tortura, discriminação, etc.), a persistência de velhas estruturas contra os direitos da pessoa humana (escravidão, trabalhos forçados, etc.), bem como as novas formas de agressão aos direitos e liberdades surgidas nos últimos anos (terrorismo, sequestro de pessoas, violação das liberdades por meio da tecnologia de informática, etc.), servem-se de constantes lutas em assegurar a todos os homens, independentemente de sua raça, local de nascimento ou ideologia, um catálogo básico de direitos e liberdades ${ }^{49}$.

Reafirma-se que desde a ocorrência das duas guerras mundiais, em decorrência dos horrores cometidos durante esse período, os direitos humanos constituem um dos temas principais do direito internacional contemporâneo. A isso se acrescentam, no atual contexto em que todos se encontram, o fato de a globalização e o consequente estreitamento das relações internacionais, principalmente perante o assustador alargamento dos meios de comunicação e do crescimento do comércio internacional.

A normatividade internacional de proteção dos direitos humanos conquistada por meio de incessantes lutas históricas e consubstanciada em inúmeros tratados concluídos com este propósito (salvaguardar os direitos humanos) foi fruto de um lento e gradual processo de internacionalização e universalização desses mesmos direitos.

O Direito Internacional dos Direitos Humanos (International Human Rights Law), fonte da moderna sistemática internacional de proteção de direitos, tem como o seu primeiro e mais remoto antecedente histórico os tratados de paz de Vestfália de 1648, que colocaram fim à Guerra dos Trinta Anos. Mas pode-se dizer que os precedentes históricos mais concretos do atual sistema internacional de proteção desses mesmos direitos são o direito humanitário, a Liga das Nações e a Organização Internacional do Trabalho, situados pela doutrina como os marcos mais importantes da formação do que hoje se conhece por arquitetura internacional dos direitos humanos ${ }^{50}$.

49 LUÑO, Antonio Enrique Pérez. Op. cit., p. 41-42.

50 MAZZUOLI, Valério de Oliveira. Curso de direito internacional público. 2. ed. rev., atual. e ampl. São Paulo: RT, 2007. p. 678. No mesmo sentido, conferir as exímias explicações de Flávia Piovesan (PIOVESAN, Flávia. Direitos humanos e o direito constitucional internacional, p. 107 et seq.). 
O direito humanitário, criado no século XIX, é aquele aplicável no caso de conflitos armados (guerra), cuja função é estabelecer limites à atuação do Estado com vistas a assegurar a observância e cumprimento dos direitos humanos. A proteção humanitária visa a proteger, em caso de guerra, militares postos fora de combate (feridos, doentes, náufragos, prisioneiros) e populações civis, devendo os seus princípios serem hoje aplicados quer às guerras internacionais, quer às guerras civis e a quaisquer outros conflitos armados ${ }^{51}$.

O segundo reforço à concepção da necessidade de relativização da soberania dos Estados foi a criação, após a Primeira Guerra Mundial (1914-1918), da Liga das Nações, cuja finalidade era a de promover a cooperação, a paz e a segurança internacionais ao condenar as agressões externas contra a integridade territorial e independência política de seus membros. A Convenção da Liga das Nações, de 1920, como leciona Flávia Piovesan, "continha previsões genéricas relativas aos direitos humanos, destacando-se as voltadas ao mandate system of the League, ao sistema das minorias e aos parâmetros internacionais do direito do trabalho - pelo qual os Estados comprometiam-se a assegurar condições justas e dignas de trabalho para homens, mulheres e crianças", sendo certo que tais dispositivos "representavam um limite à concepção de soberania estatal absoluta, à medida que a Convenção da Liga estabelecia sanções econômicas e militares a serem impostas pela comunidade internacional contra os Estados que violassem suas obrigações", fator este que veio redefinir, dessa maneira, "a noção de soberania absoluta do Estado, que passava a incorporar, em seu conceito, compromissos e obrigações de alcance internacional, no que diz respeito aos direitos humanos ${ }^{\prime \prime 2}$.

Entretanto, o antecedente que mais contribuiu para a formação do Direito Internacional dos Direitos Humanos foi a Organização Internacional do Trabalho (OIT). Criada após a Primeira Guerra Mundial, tinha por finalidade promover padrões internacionais de condições de trabalho e bem-estar social. Desde a sua fundação, em 1919, a OIT já conta mais de uma centena de convenções internacionais promulgadas, às quais os Estados-partes, além de aderir, comprometiam-se a assegurar um padrão justo e digno nas condições de trabalho ${ }^{53}$.

Ante esse breve escorço histórico, pode-se aduzir que esses três precedentes contribuíram em conjunto para a ideia de que a proteção dos direitos humanos deve ultrapassar as fronteiras estatais, transcendendo os limites da

51 PIOVESAN, Flávia. Direitos humanos e o direito constitucional internacional, p. 109-110.

52 Idem, p. 110-111.

53 Idem, p. 111. Em sentido contrário, tem-se a opinião da Professora Rossana Rocha Reis, para quem o que marca a formação do Direito Internacional dos Direitos Humanos é, de modo geral, a assinatura da Carta de fundação da Organização das Nações Unidas (ONU) em 1945, a carta de fundação do Tribunal de Nuremberg (1945-1946) e a Declaração Universal dos Direitos Humanos (1948). Segundo a pRofessora Rossana Rocha Reis, todas elas são consideradas marcos fundadores do Direito Internacional dos Direitos Humanos (REIS, Rossana Rocha. Os direitos humanos e a política internacional. Revista de Sociologia e Política, Curitiba, n. 27 , p. 33 , nov. 2006). 
soberania territorial dos Estados para alçar à categoria de matéria de ordem internacional. Eles registram o fim de uma época em que o Direito Internacional estava adstrito à regulamentação das relações estritamente estatais ao romper com o conceito de soberania estatal absoluta (que concebia o Estado como ente de poderes ilimitados, tanto interna como internacionalmente), admitindo intervenções externas no plano nacional a fim de assegurar a proteção de direitos humanos violados, ou seja, essa nova concepção deixa de lado o velho conceito de soberania estatal absoluta que considerava, na acepção tradicional, como sendo os Estados os únicos sujeitos de direito internacional público. Apenas uma exceção a essa concepção tradicional de soberania absoluta era conhecida no Direito Internacional, antes do surgimento do Direito Internacional dos Direitos Humanos, e dizia respeito à responsabilidade dos Estados por danos a estrangeiros em seu território, quando se reconhecia que tratamento conferido a determinado estrangeiro em dado Estado era interesse legítimo do governo da nacionalidade daquele estrangeiro. De modo que uma ofensa perpetrada a um cidadão italiano, em território de outro Estado, por exemplo, constituía-se em uma ofensa à própria República Italiana ${ }^{54}$.

No sentido pontificado anteriormente, em conformidade com a análise do Professor italiano Paolo Mengozzi, na comunidade internacional, os ideais humanitários foram durante longo tempo e normalmente invocados somente em relação ao tratamento dos estrangeiros, mais esporadicamente em relação ao tratamento de indivíduos que faziam parte de minorias étnicas ou de grupos religiosos. A grande importância que os Estados, os membros de base da comunidade internacional, atribuíram à defesa da própria soberania e, por consequência, ao respeito dos outros fez com que eles tivessem atuado pela promoção e pela tutela dos direitos humanos somente quando seus direitos estavam em jogo, a fim de dar proteção diplomática aos próprios súditos no exterior ou para solidarizar-se com indivíduos ligados à população nacional por particulares vínculos de ordem étnica, linguística ou religiosa ${ }^{55}$.

É nesse cenário que começam os primeiros delineamentos do Direito Internacional dos Direitos Humanos ao afastar a ideia de soberania absoluta dos Estados, em seu domínio reservado, e ao erigir os indivíduos à posição de sujeitos de direito internacional, dando-lhes mecanismos processuais eficazes para a salvaguarda de seus direitos internacionalmente protegidos ${ }^{56}$.

54 Idem, p. 113 et seq.

55 MENGOZZI, Paolo. Direitos humanos. In: BOBBIO, Norberto; MATTEUCCI, Nicola; PASQUINO, Gianfranco. Dicionário de política. Trad. Carmen C. Varriale et al. 11. ed. Brasília: UnB, v. 1, 1998. p. 355.

56 Como explica Antônio Augusto Cançado Trindade: "Na fase 'legislativa', de elaboração dos instrumentos de proteção dos direitos humanos, os mecanismos de implementação simplesmente não teriam, com toda a probabilidade, sido estabelecidos se não tivesse superado, gradativamente e com êxito, a objeção com base no chamado domínio reservado dos Estados. Esse fator fez-se acompanhar do gradual reconhecimento e cristalização da capacidade processual internacional dos indivíduos, paralelamente à gradual atribuição ou asserção da capacidade de agir dos órgãos de supervisão internacionais" (CANÇADO TRINDADE, Antônio Augusto. Op. cit., p. 5). Em outro artigo, o Ex-Juiz da Corte Interamericana de Direitos Humanos com sede em San José (Costa Rica), Professor Cançado Trindade, escreve que uma das maiores conquistas da proteção 


\subsection{A Declaração Universal dos Diretios Humanos de 1948}

A Declaração Universal dos Direitos Humanos foi adotada em 10 de dezembro de 1948, pela aprovação unânime de 48 Estados, com 8 abstenções. A inexistência de qualquer questionamento ou reserva feita pelos Estados aos princípios da Declaração, bem como de qualquer voto contrário às suas disposições, confere à Declaração Universal o significado de um código e plataforma comum de ação. A Declaração consolida a afirmação de uma ética universal ao consagrar um consenso sobre valores de cunho universal a serem seguidos pelos Estados ${ }^{57}$.

Em consonância com a lição expendida por Flávia Piovesan, a Declaração Universal dos Direitos Humanos de 1948 objetiva delinear uma ordem pública mundial fundada no respeito à dignidade da pessoa humana ao consagrar valores básicos universais. Desde seu preâmbulo, é afirmada a dignidade inerente a toda pessoa humana, titular de direitos iguais e inalienáveis. Vale dizer, para a Declaração Universal, a condição de pessoa é o requisito único e exclusivo para a titularidade de direitos. A universalidade dos direitos humanos traduz a absoluta ruptura com o legado nazista, que condicionava a titularidade de direitos à pertinência à determinada raça (a raça pura ariana). A dignidade da pessoa humana como fundamento dos direitos humanos é concepção que, posteriormente, viria a ser incorporada por todos os tratados e declarações de direitos humanos, que passaram a integrar o chamado Direito Internacional dos Direitos Humanos ${ }^{58}$.

Além da universalidade dos direitos humanos, de acordo com Flávia Piovesan, a Declaração de 1948 ainda introduz a indivisibilidade desses direitos ao ineditamente conjugar o catálogo dos direitos civis e políticos com o dos direitos econômicos, sociais e culturais. Ainda para ela, concebida como a interpretação autorizada dos arts. 1ำ (3) e 55 da Carta da ONU, no sentido de aclarar, definir e decifrar a expressão "direitos humanos e liberdades fundamentais", a Declaração de 1948 estabelece duas categorias de direitos - os direitos civis e políticos e os direitos econômicos, sociais e culturais -, combinando-se, assim, o discurso liberal e o discurso social da cidadania ao conjugar o valor da liberdade com o valor da igualdade ${ }^{59}$.

internacional dos direitos humanos, em perspectiva histórica, é, sem dúvida, o acesso dos indivíduos às instâncias internacionais de proteção e o reconhecimento de sua capacidade processual internacional em casos de violações dos direitos humanos (CANÇADO TRINDADE, Antônio Augusto. Dilemas e desafios da proteção internacional dos direitos humanos no limiar do século XXI. Revista Brasileira de Política Internacional, Brasília, v. 40, n. 1, p. 170, 1997).

57 PIOVESAN, Flávia. Direitos humanos e o direito constitucional internacional, p. 130.

58 Idem, p. 131

59 Idem, ibidem. Carlos Weis ensina que a característica da indivisibilidade ou da interdependência não distingue direitos civis e políticos com os econômicos, sociais e culturais, pois a realização de um direito pode depender do respeito e promoção de diversos outros, independentemente de sua classificação (WEIS, Carlos. Direitos humanos contemporâneos. São Paulo: Malheiros, 1999. p. 118). 
Seja por fixar a ideia de que os direitos humanos são universais, decorrentes da dignidade da pessoa humana e não derivados das peculiaridades sociais e culturais de determinada sociedade, seja por incluir em seu elenco não só direitos civis e políticos, mas também sociais, econômicos e culturais, a Declaração Universal de 1948 demarca a concepção contemporânea dos direitos humanos.

A Declaração Universal tem sido concebida como interpretação autorizada da expressão "direitos humanos e liberdades fundamentais", constante da Carta das Nações Unidas, apresentando, por esse motivo, força jurídica vinculante, embora seja somente uma recomendação das Nações Unidas, adotada sob a forma de resolução de sua Assembleia-Geral, que consubstancia uma ética universal em relação à conduta dos Estados no que tange à proteção internacional dos direitos humanos. Os Estados-membros das Nações Unidas têm, assim, a obrigação de promover o respeito e a observância universal dos direitos proclamados pela Declaração. Nesse sentido, estabelece o art. 28 da Declaração que todos têm direito a uma ordem social e internacional em que os direitos e liberdades sejam plenamente realizados ${ }^{60}$.

Pode-se acrescentar, na esteira do pensamento de Valerio de Oliveira Mazzuoli, que a Declaração Universal, por ser a manifestação das regras costumeiras universalmente reconhecidas em relação aos direitos humanos, integra as normas de jus cogens internacional, em relação às quais nenhuma derrogação é permitida, a não ser por norma de jus cogens posterior da mesma natureza, por deterem uma força anterior a todo o direito positivo ${ }^{61}$. A Declaração Universal de 1948 é uma extensão da Carta da ONU (notadamente dos seus arts. 55 e 56), visto que a integra, sendo obrigatória para os Estados-membros da ONU tornar suas leis internas compatíveis com as disposições da Declaração Universal dos Direitos Humanos de $1948^{62}$.

\section{CONCLUSÃO}

O trabalho que ora se encerra destinou-se a estabelecer os contornos fundamentais do Direito Internacional dos Direitos Humanos, bem como se apontou o processo de constitucionalização dos direitos humanos sociais nos Textos Constitucionais brasileiro e estrangeiro.

Mais importante é a compreensão de que a concepção universal dos direitos humanos não exclui as peculiaridades regionais e culturais, que, opostamente, devem servir para detalhá-los e aproximá-los das sociedades humanas, afastando, porém, qualquer redução de seu rol - tentativa que, na verdade,

60 Nesse sentido conferir: MAZZUOLI, Valério de Oliveira. Op. cit., p. 714; PIOVESAN, Flávia. Direitos humanos e o Direito Constitucional Internacional, p. 137-138.

61 MAZZUOLI, Valério de Oliveira. Op. cit., p. 714

62 Idem, ibidem. 
oculta relações de dominação e iniquidade, de todo reprováveis. Com a universalidade ou até como sua decorrência, encontra-se a transnacionalidade dos direitos humanos. Além de refletir o caráter internacional do sistema, tal característica indica que, onde quer que se encontre o ser humano, sempre possuirá direitos fundamentais, independentemente do querer estatal.

\section{REFEREANCIAS}

BOBBIO, Norberto. Marxismo. In: BOBBIO, Norberto; MATTEUCCI, Nicola;

PASQUINO, Gianfranco. Dicionário de política. Trad. Carmen C. Varriale et al. 11. ed. Brasília: UnB, v. 1, 1998.

CANÇADO TRINDADE, Antônio Augusto. A proteção internacional dos direitos humanos: fundamentos jurídicos e instrumentos básicos. São Paulo: Saraiva, 1991. Dilemas e desafios da proteção internacional dos direitos humanos no limiar do século XXI. Revista Brasileira de Política Internacional, Brasília, v. 40, n. 1, p. 167-177, 1997.

CANOTILHO, José Joaquim Gomes. "Brancosos" e interconstitucionalidade: itinerários dos discursos sobre a historicidade constitucional. Coimbra: Almedina, 2006.

COMPARATO, Fábio Konder. A afirmação histórica dos direitos humanos. 6. ed. rev. e atual. São Paulo: Saraiva, 2008.

CUNHA JÚNIOR, Dirley da. Curso de direito constitucional. 2. ed. Salvador: JusPodivm, 2008.

DALLARI, Dalmo de Abreu. Origem e atualidade do direito humanitário. Arquivos do Ministério da Justiça, Brasília, a. 51, n. 190, p. 13-27, jul./dez. 2006.

DIMOULIS, Dimitri; MARTINS, Leonardo. Teoria geral dos direitos fundamentais. São Paulo: RT, 2007.

HUNTINGTON, Samuel P. O choque de civilizações e a recomposição da ordem mundial. Trad. M. H. C. Côrtes. Rio de Janeiro: Objetiva, 1996.

JO, Hee Moon. Introdução ao direito internacional. São Paulo: LTr, 2000.

LEDUR, José Filipe. Direitos fundamentais sociais: efetivação no âmbito da democracia participativa. Porto Alegre: Livraria do Advogado, 2009.

LUÑO, Antonio Enrique Pérez. Los derechos fundamentales. 8. ed. Madrid: Editorial Tecnos, 2004.

MAZZUOLI, Valério de Oliveira. Curso de direito internacional público. 2. ed. rev., atual. e ampl. São Paulo: RT, 2007.

MENGOZZI, Paolo. Direitos humanos. In: BOBBIO, Norberto; MATTEUCCI, Nicola; PASQUINO, Gianfranco. Dicionário de política. Trad. Carmen C. Varriale et al. 11. ed. Brasília: UnB, v. 1, 1998.

NUNES JÚNIOR, Vidal Serrano. A cidadania social na Constituição de 1988: estratégias de positivação e exigibilidade judicial dos direitos sociais. São Paulo: Editora Verbatim, 2009.

PIOVESAN, Flávia. Direitos humanos e o direito constitucional internacional. 7. ed. rev., ampl. e atual. São Paulo: Saraiva, 2006.

. Temas de direitos humanos. 3. ed. São Paulo: Saraiva, 2009. 
REIS, Rossana Rocha. Os direitos humanos e a política internacional. Revista de Sociologia e Política, Curitiba, n. 27, p. 33-42, nov. 2006.

SANTOS, Boaventura de Sousa. Por uma concepção multicultural de direitos humanos. In: SANTOS, Boaventura de Sousa (Org.). Reconhecer para libertar: os caminhos do cosmopolitismo multicultural. Rio de Janeiro: Civilização Brasileira, 2003.

SARLET, Ingo Wolfgang. O direito fundamental à moradia na Constituição: algumas anotações a respeito de seu contexto, conteúdo e possível eficácia. Revista de Direito do Consumidor, São Paulo, v. 46, p. 193-233, abr./jun. 2003.

SIQUEIRA JÚNIOR, Paulo Hamilton; OLIVEIRA, Miguel Augusto Machado de. Direitos humanos e cidadania. 2. ed. rev. e atual. São Paulo: RT, 2009.

WEIS, Carlos. Direitos humanos contemporâneos. São Paulo: Malheiros, 1999. 